\title{
Axiologization of the content of training of future experts in the school-higher education institution-production system
}

\author{
Iuliia Anufrieva ${ }^{1, *}$ \\ ${ }^{1}$ Siberian Transport University, Dusi Kovalchuk st., 191, 630049, Novosibirsk, Russia
}

\begin{abstract}
The results of some tendencies of development of vocational training of employees in the school-higher education institution-production system in modern social and economic conditions are presented in the paper. The attention is paid to the unity of the main components of scientific, educational and production processes when training future experts in the system of continuous education. The directions of improvement of professional education of employees in the conditions of modernization of system of continuous education, integration into digital economy taking into account the factors impacting on formation process of valuable orientations of future experts are offered. Features of an axiologization of content of scientific and educational, production activity provide successful value and professional self-determination of future experts in new social and economic conditions.
\end{abstract}

\section{Introduction}

The main directions of improving the system of vocational training of employees in the context of modernization of the system of continuous education are associated with ensuring its greater transformation and controllability in order to meet the growing demands of the economy, modern information and production technologies.

Analysis of the current situation in the sphere of education made it possible to identify the following contradictions related to the need to form social, personal, professional value orientations of future experts and negative trends affecting their formation in society: insufficient attention to the nurturing function of education in the education system; insufficiently high level of quality indicators of the students' life; the requirements of modern science, the emerging new information technology and the insufficient orientation of education on the formation of professional value orientations of future experts.

Within the concept of the Federal state educational standards of the fourth generation, the development trends of the training system are related to the development of modern requirements to the quality and content of the training of trainees, taking into account professional standards. In this regard, some features in the system of continuous education at the present time should be noted: increasing the volume of subject-oriented classes, strengthening the requirements for mastering the basic educational programs, formation of

* Corresponding author: alex7@cn.ru 
various universal competencies: teamwork, leadership, communication, self-organization $[1,2]$. The need to meet the requirements of modern production, the emergence of new professions in various spheres of economic activity, the need to integrate educational programs with professional standards make adjustments to the training of modern employees [3; 4, p. 41].

The dynamism of modern information and technological processes and the emergence of new competencies call for the training of employees capable of combining individual values with public ones, professional interests and needs. In modern conditions, more than $80 \%$ able-bodied population of Russia does not have the skills and competencies to work in modern markets. The results of sociological research indicate that, during the job placement, young people encounter problems with lack of practical skills and special knowledge [5].

In the 21 st century, new competence groups are becoming indicators of the modern professional: "Softskills" - the ability to build social and professional communications, to learn and self-develop; entrepreneurial competence - the ability to turn ideas into actions through creativity, innovation, forecasting, making effective management decisions and assessing risks; digital competence - effective use of information and communication technologies.

\section{Materials and methods}

The economic effect of the functioning of enterprises will occur when the modernization of the system of continuous education, the technological environment, the formation of the information and technological structure will take into account social, cultural, professional problems of youth and factors that affect the changes in their professional value orientations. In the solution of this problem, an important place is taken by the formation of professional value orientations of future experts in the system "school- higher education institution -production". Innovative education within of this system presupposes the continuous development of the entire potential of the individual, the development of its abilities for joint action in unprecedented situations; skills of social adaptation in any conditions related to the specificity of professional activity on the basis of scientific and methodological support of the content of training of employees, oriented to the professional-value self-determination of the individual.

Many researchers believe that the process of formation of value orientations of students has a complex dynamic nature affecting all personality structures: cognitive, professional, emotional, and others. As the pedagogical practice and results of our studies show, the formation of value orientations of students of the system of continuous education has the character of cognitive activity and is formed at the stage of pre-university education, taking into account the features of motivation of pupils of senior classes for responsibility, professional competence, entrepreneurship [6].

The characteristic of professional value orientations of students of technical universities indicates such priority values as: responsibility, self-confidence, competitiveness, leadership. The corporate competence of the transport industry employees involves the development of such competencies as employee loyalty and responsibility; creativity and innovation; customer-oriented; quality and safety; leadership that allows the employees to work effectively in the implementation of production tasks [7].

Thus, today, in the educational system "school-higher education institution-production", among the variety of various necessary competencies, there is a need to isolate, diagnose and select professional values in a significant and quantitative way. Features of such scientific and educational activities include problem statement, diagnosis, observation, conclusions, their verification, accounting, development and implementation of scientific 
and methodological support of the content of vocational training, which ensures the successful professional development of students in the new socio-economic conditions.

Realization of stages of formation of value orientations of future experts requires the development of innovative scientific and methodological support; the allocation of key value categories: "responsibility", "leadership", "communication skills", "creativity", "selfdevelopment", "emotional intelligence", "professional culture", "teamwork", "moral qualities", "innovation", "entrepreneurial spirit". In this regard, it is necessary to design individual educational routes and career history of trainees and employees of companies. Within the framework of our research, the model of individual educational routes in the system "school-higher education institution-production" was successfully tested, taking into account the continuation and continuity of the educational and cognitive process. The results of the longitudinal study were obtained.

Issues of axiologization of the content of training of employees in the system "schoolhigher education institution-production" cover the adjustment of all educational resources, including scientific and methodical support based on the formation of value orientations of students. The scientific and methodological support includes: didactics and methodological support (innovative pedagogical technologies aimed at the formation of value orientations; raising the qualifications of the teaching personnel; recommendations on the formation of key values of the students, etc.); educational and methodological support (curriculum, work programs, funds of assessment tools with assignments for students revealing the professional values of the company, contributing to the development of motivation); information and technological support (visual and technical means of teaching that contribute to the formation of digital competencies of students).

\section{Results}

Our study of the formation of value orientations of future economists included an assessment of changes in personal, motivational and activity components at all stages of their training before and after the use of specially developed scientific and methodological support. During the study, at the stages of formation of value orientations of future experts with the aim of activating value and motivational attitudes, we used modern forms and methods of educational and cognitive process that develop the skills of teamwork, as well as interpersonal and intercultural network communication; decision-making in professional social situations; the identification of factors that characterize attitudes towards work and others; modern rating systems (rating, integrated, electronic), etc. The development of the motivation of each student by providing him with all the educational elements provides opportunities for the disclosure of his individual abilities and talents.

Based on the analysis, it can be concluded that effective management of changes in the educational and cognitive process is provided on the basis of: an analysis of internal and external factors; pedagogical risks; combination of various modern educational models of training (network, virtual, remote); use of various funds of assessment tools (computational and graphic and simulation tasks; business games; trainings; modeling of socio-economic, managerial motivational situations (case study); development of scientific projects; assignments for practice with strengthening the engineering component; individual plans for final qualification works, portfolio); use of technical and information means of education; self-realization of students through participation in olympiads, projects, grants, conferences, round tables, etc.

The format of the conference - the formation of focus groups - allows summarizing the results of studies of students on the basis of materials obtained during the educational and production practices, personal experience of practical activities of students. During a group 
discussion, aspects of the indicated topic, which reveal the content of professional values of companies, are discussed.

The implementation of the pre-university and university stages in the formation of value orientations of future experts made it possible to test the content of scientific and methodological support in various disciplines: "Technology of professional career. Effective behavior in the labor market", "Corporate social responsibility", "Labor economics", "Transport economics", "Leadership and change management", "Motivation and encouragement of workers' activities", "Outsourcing in transport", "Methodology for organization of scientific and pedagogical activity", and also individual educational support, taking into account the allocation of value categories in various competencies in the training of economic employees.

The results of the questioning of school teachers and university professors showed the success of the implementation of scientific and methodological support, the high level of the formation of professional value orientations of future experts on the basis of a specially organized educational process.

To the question: "What do you understand by axiological analysis of the content of the training of future experts?" the respondents gave different answers:

- "the concept of humanistic pedagogy;

- continuation, continuity of education;

- education through training;

- educational and methodological content of disciplines, aimed at the formation of life and professional value orientations of students;

- formation of professional and value self-determination of students".

A special role in the quality management of professional educational services is assigned to the personality of the school and university teacher, the production mentor.

A modern teacher is like a manager of a company. He must achieve the conformity of the form and organization of the content of training, the obligatory use of innovative educational methods in the educational and training process, the teacher's ability and readiness for pedagogical risk, understanding of the unity of education, science, culture, attitude development and self-education $[6, \mathrm{p} .6]$.

\section{Conclusions}

The results of the questioning of teachers and professors indicated the need to change the educational activities of a modern teacher and professor:

- readiness for pedagogical risks (for innovations in teaching);

- the need to study modern pedagogical methods and the form of organization of the educational process;

- readiness for dialogue with students, individualization of training;

- readiness for self-improvement, professional growth;

- knowledge of the specifics of the diagnosis of the formation of value orientations of students during the educational process.

It should be noted that the successful management of the modern pedagogical process is the consideration of factors and risks that affect the quality and content of scientific and methodical support on the basis of the formation of professional value orientations of future experts.

Therefore, the process of improving the professional training of employees in the system of "school- higher education institution-production" should include axiological foundations for the content of educational programs aimed at developing creative and leadership potential, systemic and critical thinking, business activity of future experts 
through the formation of individual educational trajectories, which allows giving education a new direction in the current socio-economic conditions.

\section{References}

1. The Russian Federal state educational standard of the higher education of the direction of preparation 38.04.01 Economy (level a magistracy) (the FGOS project - 4), http:// regulation.gov.ru

2. The federal state educational standard of the higher education of the direction of preparation (the FGOS project - 4), http:// regulation.gov.ru

3. Yu.V. Anufriyeva, The World of science, culture, education 1-68, 175-178 (2018)

4. N.B. Sueva, Professional education. Capital 4, $41-42$ (2016)

5. L.V. Shmelkova, Additional professional education in the country and the world $\mathbf{8 ( 3 0 )}$, $1-4$ (2016)

6. V.F. Glushkov, Yu.V. Anufrieva, The World of science, culture, education 1(50), 5 - 7 (2015)

7. Model of corporate competences of JSC "Russian Railways": protocol No. KR-2 of 29.06.2010 